\title{
FLOATING OFFSHORE WIND TURBINES - TECHNOLOGY AND POTENTIAL
}

\author{
Aurel - Dan Maimon \\ University "Dunarea de Jos" of Galati, \\ Faculty of Naval Architecture, Galati, \\ Domneasca Street, No. 47, 800008, Romania, \\ E-mail:dan.maimon@ugal.ro
}

\begin{abstract}
The main purpose of this paper is to present a short review of the actual progress on the floating offshore wind turbines. Floating offshore wind turbines have several advantages: overcoming the depth constraint, floating offshore wind turbines can be installed further offshore and therefore on the one hand have little or no visual impact from the coast, and on the other hand to take advantage of more constant and stronger winds, thus increasing the production efficiency of electricity. They are assembled to port and then transported to site with an ordinary tug, which can also bring them ashore for heavy maintenance or final dismantling. Floating wind power is the future of offshore wind power.
\end{abstract}

Keywords: floating wind turbines, wind energy, anchoring, oscillations, stability

\section{INTRODUCTION}

Several countries around the world started an energy transition very early, giving a major place to renewable energy sources. Considering the natural limits of bioenergy or geothermal energy, electricity from renewable sources has emerged as the preferred route; thanks to technical progress and lower costs, two new production methods, wind and photovoltaic, have quickly acquired significant shares in energy balances.

The pursuit of this orientation, even the search for a mix exclusively renewable electricity, has pushed European states with a maritime area to exploit its potential. I was highlighted the pioneering role of Europe in the offshore wind industry. At the end of 2018, the EU countries and Norway represented $79 \%$ of the installed offshore wind capacity worldwide, with a connected capacity of 18.3 GW.

There are studies emphasized that this performance was based on a local peculiarity, the existence of a shallow and well windy area in the southern half of the North Sea, with ramifications in the Irish Sea and the Baltic Sea. As a result, operators were able to transpose well-mastered technology on land, wind turbines on foundations, into the sea, which can be installed on the seabed up to a water depth of about $60 \mathrm{~m}$. Such a maritime configuration is found in a few regions of the world (including the South China Sea and the east coast of the United States), but ultimately few in number. Most of the world's windy coastal areas are surrounded by water too deep for foundation-mounted wind turbines. On the other hand, we could equip them with floating offshore wind turbines, an emerging technology. The outlets for this technology appear immense, with very high technical potential for Europe and for the west coast of the United States in particular, and an accessible market of $100 \mathrm{GW}$ by 2050 .

This paper examines this new sector and briefly reviews the technical characteristics and the particular difficulties it faces. 


\section{TECHNICAL CHARACTERISTICS AND DIFFICULTIES TO OVERCOME}

\subsection{THE GOAL OF STABILITY}

The primary objective of any designer of floating offshore equipment is to provide the greatest possible stability to their product. When a floating platform undergoes oscillations with the swell, it exerts a traction followed by a release on the anchoring devices and on the components that connect it to the mainland (pipes or electric cables). Such alternation causes "fatigue" of the materials, which degrade much more quickly than by supporting a constant force (permanent traction or compression).

Fatigue is increased in the case of floating wind turbines due to vibrations linked to the rotation of the blades. These vibrations occur as soon as the axis of rotation comes out of strict alignment with the direction of the wind; they are observed on all wind turbines, including on land during turbulent winds. In the case of a floating wind turbine, in addition to fluctuations in the wind, there are any movements of the float, which can cause a pivoting around the vertical axis (yaw), a sway back and forth (roll) or to port on starboard (pitch).

Furthermore, the rotation of a turbine seems regular, but it is not perfectly: when a blade passes in line with the mast, the wind pressure is altered, occasionally modifying the balance of forces. The repetition of this alteration also induces a vibration in the support. The oscillations of the whole can gain in amplitude if the movement caused by the swell is combined with that created by the rotation to generate a phenomenon of mechanical resonance. The risk of resonance exists for offshore wind turbines on foundations subjected to the regular shock of waves, but the rooting in the ground ensures energy diffusion and limits the amplitude of the oscillations. In addition, floating installations are often intended to be installed in areas exposed to swell and stronger winds than foundation wind turbines.

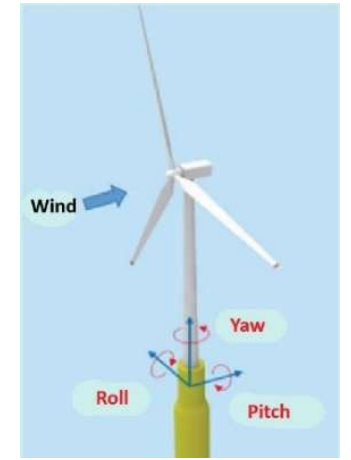

Fig.1. The three axes of movement

\subsection{ANCHORING}

The main quality required of a float therefore concerns the stability it gives to the installation, in order to reduce oscillations and, in so doing, minimize material fatigue. Two important factors combine to improve stability: the lowering of the center of gravity and the anchoring of the assembly. As a result, a float is immediately designed with its anchoring system.

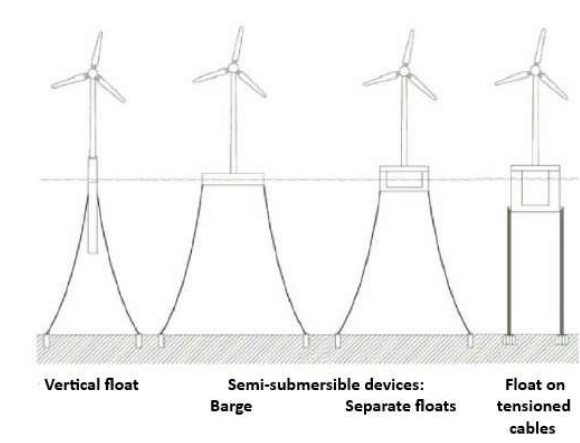

Fig.2. Four examples of floats with their anchors

The simplest anchoring consists of several chains which end either in a marine anchor or a very heavy solid placed on the ground, the weight of which slows down the movements of the float, or by a seal on the seabed, the safest technology for avoid slipping. Sealing is often done by means of a suction anchor, a kind of hollow cylinder that sinks vertically into the ocean floor. Each chain is most often connected to the float by a metal or synthetic fiber cable. The cables can 
be anchored directly to the ground, but in this case the number of cables and seals must be increased. Some floats are designed for cables stretched vertically; this technique provides excellent stability but it assumes a very robust tie-down point on the seabed, more complex to make and more expensive than other devices, and it makes subsequent disconnection difficult for heavy maintenance needs.

Whatever the solution, we choose materials with a high resistance to fatigue and corrosion, the latter coming both from the saline environment and from the rapid colonization of the components submerged by oceanic flora and fauna.

\subsection{EVACUATION OF THE CURRENT PRODUCED}

In the case of wind turbines on foundations, the electric current is evacuated by means of a cable connecting each wind turbine to a substation, at a voltage of 33 or 66 kilovolts $(\mathrm{kV})$, depending on the power of the turbines. From the substation, a higher voltage cable (typically $150 \mathrm{kV}$ ) joins the mainland. All these cables are static and suitable for alternating current.

In the case of a floating wind turbine, the oscillations of the installation are reflected in the cables, which undergo a permanent movement: we now speak of "dynamic cables". Experience with floating offshore installations in the oil industry teaches that the greatest stresses are manifested at the head of the cable, that is to say at the point of connection with the part fixed to the float.

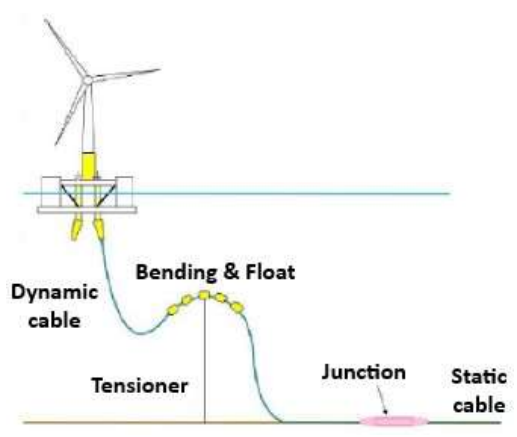

Fig.3. Principle of electrical connection
To reduce these stresses, and therefore the fatigue of this part of the cable, it is necessary to give an "s" shape to the section located just before the connection, thanks to a bending device with floats and tensioner, a technology perfectly mastered in the offshore oil tanker.

In the current state of technology, we know how to make cables dynamic up to a voltage of $66 \mathrm{kV}$; current can therefore be channeled from a floating wind turbine. In contrast, higher voltage cables use insulation and exterior coatings of a different composition, which poorly tolerate fatigue. The design of a floating substation therefore supposes overcoming serious difficulties if it is to be equipped with a dynamic $150 \mathrm{kV}$ alternating current cable, for example, going to the shore. The outlook remains encouraging in the medium term, as a dynamic $115 \mathrm{kV}$ cable has been successfully tested since 2010 by the $\mathrm{ABB}$ group to supply alternating current to the Gjoa floating platform, operated by Equinor (ex-Statoil), intended for the oil and gas extraction in the northern part of the North Sea The ABB group reached a new milestone in 2013, with the development of a dynamic 123 $\mathrm{kV}$ cable serving the Goliat floating platform, jointly operated by ENI and Equinor in the Barents Sea, again for gas and oil.

Finally, the French companies Ideol and Atlantique Offshore Energy (a subsidiary of the Chantiers de l'Atlantique group) unveiled on June 4, 2019 a complete floating substation project, designed in cooperation with $\mathrm{ABB}$, which marks new progress.

Note that it would also be possible to convert alternating current into direct current, the technology of which lends itself better to dynamic cables. In a long-term vision, one could imagine that the substation would convert electricity into hydrogen, which would be evacuated by ship, allowing the installation of floating wind turbines very far from the shore.

The part of the cables which rest on the seabed is always protected, either by burial in the sediment, or by riprap, or even by a cover made up of concrete or cast iron parts. Some projects provide that the section on the ground 
can be disconnected from that which descends from the wind turbine or from the substation. This manoeuvrable junction would thus play the role of a household appliance's outlet, which can be disconnected when necessary. The possibility of connecting or disconnecting the installations induces an additional cost, but it offers several advantages: it makes it possible to program the laying of the cables on the seabed before the arrival of the machines, to disconnect them to bring them back to land for purposes of maintenance and finally to avoid tearing of cables in the event that a wind turbine breaks its anchor and starts to drift.

\section{FIRST STEPS}

Attracted by the prospect of a sizeable market and pushed by governments keen to promote a new source of clean energy, several industrial players have been studying the floating offshore wind industry for more than a decade in a multi-step process. At the end of a preliminary computer phase, when the studies prove to be engaging, we move on to the production of a full-scale prototype reduced, then to the construction of an industrial-size demonstrator and then to the commissioning of a pre-commercial installation. The success of each stage of course conditions the passage to the next. There are projects in the world that are at each of the four stages summarized above; none have reached the ultimate stage, which would be to compete under market conditions.

The demonstrator stage followed the timeline below:

2009: The first industrial-scale installation was launched off Karmoy (Norway) by the Statoil group (now Equinor). Called Hywind Demo, it included a vertical float and a 2.3 MW turbine supplied by Siemens, not specifically designed for this use.

2011: The Portuguese group EPD Renovàveis (EDPR), associated with the Spanish oil and gas operator Repsol, then commissioned in Aguçadoura, on the Portuguese coast, the WindFloat model, equipped with a semi-submersible float designed by the
American group Principle Power Inc. and a 2 MW Vestas turbine, also from the regular range.

2016-2018: Japan took over, with four demonstrators of different models, installed one in Goto-Kabashima (2 MW), two in Fukushima (5 MW), all equipped with Hitachi turbines, and one in Kitakyushu (2 MW), implementing a semi-submersible barge of Ideol design with a two-blade turbine.

2018: France connected to the grid in 2018 , on the one hand, the Floatgen wind turbine, off Croisic, equipped with a 2 MW turbine delivered by Vestas mounted on a semisubmersible barge with a concrete hull designed by Ideol and built by the Bouygues group and, on the other hand, the innovative Eolink model.

We note that the three European pioneers have formed consortia in which at least one player has experience in the exploration and production of hydrocarbons at sea (Equinor, Repsol and Ideol). Indeed, large floating industrial structures have been around for a long time in the offshore oil and gas industry. They are often used as support for loading or unloading installations at sea, near drilling platforms or ports. Depending on the needs, various types of floats have been developed, combined with various types of anchors to prevent the installation from drifting with the currents. These models have been proven to withstand the constant onslaught of waves, sometimes including storm surges, even typhoon waves or even "rogue waves" of enormous height.

Their approach has attracted other service providers from the oil and gas industries, who in turn have designed models that will soon be in the demonstration phase. Two examples will be cited here, coming from manufacturers convinced that the floating wind market will develop rapidly and that components should be standardized for inexpensive mass production. Both are relatively easy to assemble modular floats:

- The Shell group, associated with the German operator Innogy, should test in 2020 the Tetraspar model, designed by the operator 
Stiesdal, also German, off the coast of Norway, with a Siemens-Gamesa 3.6 MW turbine.

- The Italian group SAIPEM plans to commission its Hexafloat model in 2022 on the west coast of Ireland. The manufacturer indicates that its float will be delivered as a kit and that it can receive any conventional turbine up to $15 \mathrm{MW}$.

All the players mentioned above have transferred a long-proven competence to a new sector of activity. They thus minimize the risks, but this choice has a downside: it leads to ignoring the most innovative projects, led by newcomers. The difficulty in penetrating the latter comes from research work carried out in small structures, laboratories or universities without sufficient links with large companies, thus encountering obstacles to raising capital.

\subsection{INNOVATIVE PROJECTS}

More than thirty models of floating wind turbines have been studied and several have passed the prototype stage. We can cite two achievements at the demonstrator stage: the Eolink project, currently being tested off Saint-Anne-du-Portzic (France) since 2018 and the X1Wind project, the testing phase of which will begin in the Canary Islands. (Spain). These are two very innovative models, which use turbines designed exclusively for floating bases, with metal joist supports, much lighter than ordinary masts, conforming to the edges of a pyramid (Eolink) or a tetrahedron (X1Wind). Maintained on site by a single anchor point, they spontaneously orient themselves into the wind, which in turn reduces the cost of control devices and improves the load factor. In addition, the Eolink model offers a large distance between the end of the blades and the four supports (distance marked "d" in figure 4); the risk of impact being less, it is possible to choose lighter materials for these blades; being less heavy, their rotation causes less fatigue in the structure. Eolink and $\mathrm{X} 1 \mathrm{Wind}$ will now have to prove the reliability of the electrical connection, subject to higher degrees of freedom than on installations with several anchor points.

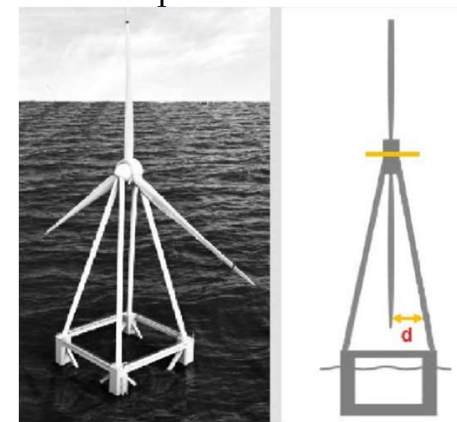

Fig.4. The specificities of the Eolink model

The SeaTwirl project constitutes an even greater break with the concepts in force to date, since it uses a vertical axis turbine, according to the principle studied by Georges Darrieus. By placing the rotor very close to sea level, this model significantly lowers the center of gravity of the installation. Therefore, a float of small proportions is enough to guarantee its stability, and the float represents a high fraction of the cost of a floating wind turbine. The position in the lower part of the rotor also facilitates maintenance operations.

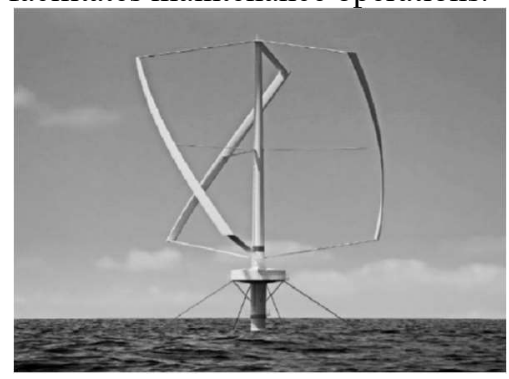

Fig.5. The SeaTwirl model

The final advantages are that Darrieus wind turbines adapt to rotating winds and appear insensitive to the wake effect, which allows them to be installed at a short distance from each other and reduces the influence on the maritime domain. This design also limits the impact of roll and pitch.

The SeaTwirl project has received financial support from the Norwegian group NorSea, specialist in offshore logistics, and the Belgian group Colruyt, whose subsidiary Parkwind operates large offshore wind farms on foundations in the North Sea. SeaTwirl 
plans to commission a $1 \mathrm{MW}$ demonstrator on the Norwegian coast in 2020.

Finally, the Swedish group Hexicon is piloting the creation of a $10 \mathrm{MW}$ demonstrator using a semi-submersible triangular-shaped float common in the oil industry. On two vertices of the triangle we will place a $5 \mathrm{MW}$ wind turbine; to always stay upwind, the assembly will pivot around the third peak, where the anchor and the power cable will leave. The launch is scheduled for early 2020 at the Dounreay Tri site in Scotland.

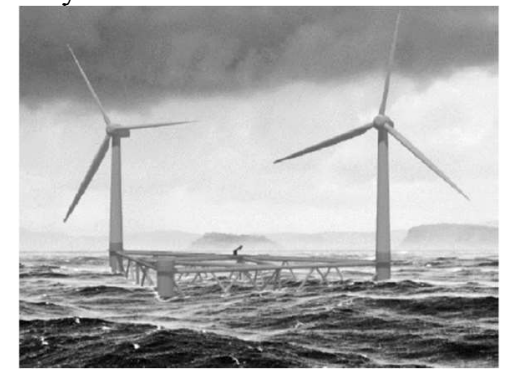

Fig.6. The Hexicon model

\section{CONCLUDING REMARKS}

In a world called upon to accelerate the decarbonisation of its economic and energy sectors to follow a trajectory compatible with the Paris agreement, floating offshore wind technology appears to be one of the most promising on a large scale. It opens up access to an immense resource, relatively well distributed on the surface of the globe and available over long periods while exerting a moderate environmental impact. This technology still requires progress; it concerns a hostile natural environment and uses equipment whose development has not yet been completed.

Several European countries have revealed the potential for rapid progress in the sector, although the proof of viability is not yet complete; better still, their first tests led to the conviction that cost reductions are accessible in the medium term, likely to make this technology competitive against its rivals in the field of renewable energies. Four countries have reached the pre-commercial stage, with farms of a significant size, capable of validating the different models of floats and preparing responses to future calls for tenders: France, Norway, Portugal and the United Kingdom (Scotland ). However, these States are reluctant to make the additional effort which will remain essential for a few more years to achieve a decisive reduction in costs.

The floating offshore wind farm has the characteristics of a sector of the future, because it concerns a global market and because it retains considerable scope for improvement.

While concerns are expressed more and more frequently about the maintenance of an industrial sector alive in Europe, the floating offshore wind sector deserves to be considered as strategic.

\section{REFERENCES}

[1]. Bracq, G., "L'eolien offshore flottant", in IFM Méditerranée, Revue Maritime, November, 2016.

[2]. Burton, T., et al., "Wind energy handbook", Wiley Online Library, 2001.

[3]. Cruciani, M., "L'éolien offshore flottant dans sa dimension industrielle et technologique", Études de l'Ifri, IFRI, 2010.

[4]. Gueydon, S. \& Weller, S., "Study of a floating foundation for wind turbines", Proceedings of the ASME 2012 31st International Conference on Ocean, Offshore and Artic Engineering, 2012.

[5]. Pourcher, E. et al., "Éolien flottant: à la conquête du large!", Les notes de l'Observatoire des énergies de la mer du Cluster Maritime Français \#7, September, 2020.

[6]. Roddier, D., et al., "WindFloat: A floating foundation for offshore wind turbines", Journal of Renewable and Sustainable Energy, 2010.

Paper received on October $30^{\text {th }}, 2020$ 